\title{
Promoting Phetchaburi Tourism Using the Royal Projects Trail Tourism Application as a Main Tool
}

\author{
Attama Boonpalit, Nitikorn Maungsornkaew \\ ${ }^{1,2}$ Faculty of Management Science Silpakorn University, Thailand
}

\begin{abstract}
Aware of the lack of tourism trial and marketing, this project aimed to develop a Phetchaburi Royal Projects Trail Application to accommodate convenience tourists' information finding. It was hope that this application can be used as a main tool to promote Phetchaburi tourism. This project divided the study into 2 phases. Phase 1: A Royal Projects' Trail application was developed based on primary and secondary data. It was designed to be easy to use and fit the mobile screen with simply functions. Phase 2: Using PAR (Participatory Action Research) techniques such as workshops to enhance tourism development stakeholders' participation by providing opportunities for giving information and gaining knowledge about how to market tourism via mobile app. From the 3 workshops, there were a total of 113 cooperatives' members from Cha-am District, Tayang District and Talard District attending the workshops.

It can be concluded that to initiate networking among tourism stakeholders in Phetchaburi Province we should begin with the cooperatives organizations in the areas for public relation and coordination to their members because the majority of farmers in Phetchaburi are members of the local cooperatives. Members of the cooperative are voluntarily involved in activities recommended by the organization. In addition, every cooperative organizations in Phetchaburi working in coordination with others, therefore; starting the public relation of the mobile app to the three cooperative organizations is a good start to sustain the app by extending users to other cooperatives, sponsored the app and moving toward smart city and smart tourism destination.
\end{abstract}

Key words: Royal Project, Mobile Application, Mobile Marketing, Sponsored Data, Smart Tourism 


\section{Introduction}

Phetchaburi Province is one of the secondary tourism destinations located in the lower middle part of Thailand. With many attractive tourist destinations including historical, cultural, local life and natural attractions; many researches under innovative development project were funded. Those funded projects aimed to develop local communities in Phetchaburi in terms of knowledge center, products and services development. However, the gaps occurred in terms of connection of the products and services to tourism trials and how to promote those products and service, so contribution from those funded projects may be less than expected.

\footnotetext{
${ }^{1,2}$ First and second author affiliation
}

Since there are more than 20 of the King Rama the $9^{\text {th }}$ Projects in Phetchaburi and some of these Royal Projects are famous to tourists such as Hub Kapong and Chang Hua-Man. Besides the contribution of many benefits to communities, the Royal Projects are also recognized as education and recreation tourism destinations. Aware of the lack of tourism trial and marketing, this project aimed to develop a Phetchaburi Royal Projects Trail application to accommodate convenience tourists' information finding. At the same time, connected communities' products/services to the app. It was hope that this application can use as a main tool to promote Phetchaburi tourism.

\section{Mobile Marketing}

It has been well recognized that almost all of the world population over 16 years old own smartphone, as a consequence, most of internet users frequently search via smartphone. Since the customer attention switches to smartphone screen, it is reasonably for marketers to spend their efforts on mobile channel (Mobile Marketing Association (MMA), 2014). To better understand how customer's cognitive process working helps marketers to better understand how mobile can leverage their media and creative strategies. Therefore, Mobile Marketing Association (MMA) using scientific research in neuroscience to understand cognitive process that human brain needs less than half a second to absorb and recognized mobile advertising and trigger a reaction. In addition, advertising via mobile device get faster responsiveness and stronger cognition compared to desktop. It is also recognized that video is more quickly and better engages emotional response than non-moving advertising (Mobile Marketing Association (MMA), 2019).

As the number of smartphone users is growing and changing of human behavior with the advance technology occurred (Harlaka, 2017), it was evident that the ecosystem was driven by local and global digital telecom operators such as messaging apps like WeChat (China), Line (Japan) and Hike (India); search engines like Baidu (China); and e-commerce Company like Alibaba (China), Flipkart and Snapdeal in India. Consequently, marketing strategy is moving forward from e-commerce to m-commerce (Nayyar, 2017). To enhance user experience, 
designers needs to identify how to make users complete a transaction easier, quicker and in a pleasurable way by recognizing of who are users and what their aims are (Harlaka, 2017).

\subsection{Sponsored Data and Mobile Application}

Every smartphone holders, anywhere in the world, need data (connectivity) so data feeding has been growing since. Sponsored Data is a new way to gain opportunity of advertising market to approaching customers through smartphone or mobile devices (Mense, 2017). The concept of Sponsored Data is driven by the growing of data feeding that is affected users by data cost and limited plan. Sponsored Data means to provide certain amount of data or navigation of a mobile app/site to certain users complimentarily. There are two main types of Sponsored Data called Zero Rating and Data Rewards. Organizations sponsor data usually benefit from asking customers/users to do something on requested to gain web access such as downloading and using their app, watching video clip, filling personal data, doing a survey or buying their product/service (Mobile Marketing Association (MMA), 2017).

In Zero Rating model, navigation is subsidized by content providers that consents users of accessing web/navigator without cost (Mobile Marketing Association (MMA), 2017). All social networks and messaging apps like WeChat (China), Line (Japan) and Hike (India) are example of operators that provide unlimited access and gain users' geolocation, time and behaviors. Zero Rating is only sustain in exceptional organizations because of its high costs. Commercial Bank is a good example, mobile banking apps are sustain because when any customer doing a transaction at bank counter the cost is five time as much compared to the same transaction via mobile banking.

Data Rewards is an user-oriented model that provides rewards in form of data based on users' decisions to participate in the rewards program such as downloading an app, purchasing products/services online, or playing a videogame (Mobile Marketing Association (MMA), 2017). With increasing ad blockers, Sponsored Data becomes progressively vital as strategic marketing supported by user information, context such as geolocation and data (connectivity). Since behaviors of intermediaries in the value chain changed, Sponsored Data is a win-win concept that benefits both companies and customers, therefore, producing high perceived value. Developing of a Phetchaburi Royal Projects Trail Application is to benefit both tourists and local communities in Phetchaburi Province.

\section{Smart Tourism}

"Smart Tourism" is recognized as a megatrend in tourism in term of applied technology, especially, smart tourism also being seen as a strategic development of tourism (Gretzel, Koo, Sigala, \& Xiang, 2015). Following the theme "Smart City", European Union (EU) identified smart tourism as the gather of travel information and communication to initiate an appropriate strategy in transportation (The European Commission, 2015). In economy advance countries such as China "Smart Tourism" is one of the national agenda. In order to develop economic and services quality, information technology (ICT) is applied (CNTA, 2015).

Although the definition of "Smart Tourism" is not clear, the first meeting of UN World Tourism Organization (UNWTO) in 2009 at Madrid, Spain; defined "Smart Tourism" as green, clean and ethical tourism with high quality services at every levels of supply chain (UNWTO, 
2009). In the western countries both scholars and private sectors agreed that in "Smart Tourism" concept, information technology plays important role in bridging and creating good relationship between tourists and tourism destinations while enhancing tourism stakeholders participation that leads to sustainable in tourism (Li, Hu, Huang, \& Duan, 2017).

Park, Lee, Yoo, and Nam,(2016) divided smart tourism into 3 types according to its application. First, smart tourism referred to genius services that supporting user's accessibility

to destinations. The continuously growing number of international and domestic tourists, especially, tourists traveling and planning the travel by themselves, searching of tourism information is necessary. Some travel agency add online platform for customers, for example; Smart Tourism Marketing Group in New Zealand providing customers with self-planning program (Eptein \& Vergani, 2006). Second, smart tourism using in marketing such as online marketing, marketing promotion, marketing theory and digital marketing. Others related services such as app and website are included. Third, smart tourism can also referred to the integration of technology and tourism such as reserving accommodation, restaurant and transportation through mobile app.

"Smart Tourism" starting from the fast growing of advance ICT, the new channel of borderless communication, information management, analyzed and exchange of data that added value to services and business management (Lazer et al., 2009). The last decade shown the ever growing of data searching online via internet and online marketing, including tourists' decision to book services themselves (Sigala, Christou, \& Gretzel, 2012; Xiang, Wang, O' Leary, \& Fesenmaire, 2014). These technologies have been applied direct and indirect to tourism for more than two decades, especially, the reservation system called "e-Tourism".

Grezel, Sigala, Xiang and Koo (2015) compared e-tourism and smart tourism in terms of sphere, core technology, travel phase, lifeblood, paradigm, structure and exchange as follow: e-tourism is digital while smart tourism bridging digital and physical environment. Core technology of e-tourism is website while smart tourism uses sensors and smartphone. In etourism era, tourists search information before and after their travelling while smart tourism providing real time processing big data to tourists. The exchange of information in e-tourism is between $\mathrm{B} 2 \mathrm{~B}, \mathrm{~B} 2 \mathrm{C}$ and $\mathrm{C} 2 \mathrm{C}$ which are intermediaries in value chain while smart tourism initiates public-private-consumer collaboration in tourism ecosystem.

It can be concluded that definition of "smart tourism" covers tourism development when innovation of technology are integrated (Ma \& Liu, 2011). The main component of smart tourism is the application of ICT in tourism promotion process to improve communication capability and management of infrastructure in order to enhance service innovation and governance in the destinations (Gretzel, Koo, et al., 2015; Hunter, Chung, Gretzel, \& Koo, 2015; Koo, Gretzel, Hunter, \& Chung, 2015).

Mobile technology is also applied by the use of smartphone all over the world makes information searching more convenience (Wang \& Xiang, 2012). At tourist destinations technology such as Radio-Frequency-Identification (RFID) Tags and censors are implemented to enhance tourists' experience (Azori, Iera, \& Morabito, 2010).

\subsection{Component of "Smart Tourism"}


Smart tourism encompasses various components and layers of smart as shown in Figure 1. The first component, "smart destination" applied the concept of smart city where ICT is integrated into physical infrastructure (Gretzel, Sigala, Xiang, \& Koo, 2015), for example; the uses of beacon in Amsterdam that translates tourists sign into different languages (http://amsterdamsmartcity.com/), Seoul provides free Wi-Fi and smartphone to tourists (http://www.visitseoul.net), and Sunmoon Lake in Taiwan provides location-based information on tourists bus. The smart city concept raises innovation, quality of life and sustainability to both tourists and local communities at the destination (Gretzel, Sigala, et al., 2015).

The "smart experience" component is a social phenomenon arising when tourist is not only get real time information (Buhalis \& Amranggana, 2014) but also actively participate in enriching data by adding their experiences such as uploading photo with hashtag or mapping minor destination to social media (Gretzel, Koo, et al., 2015).

Figure 1: Component and level of "Smart Tourism"

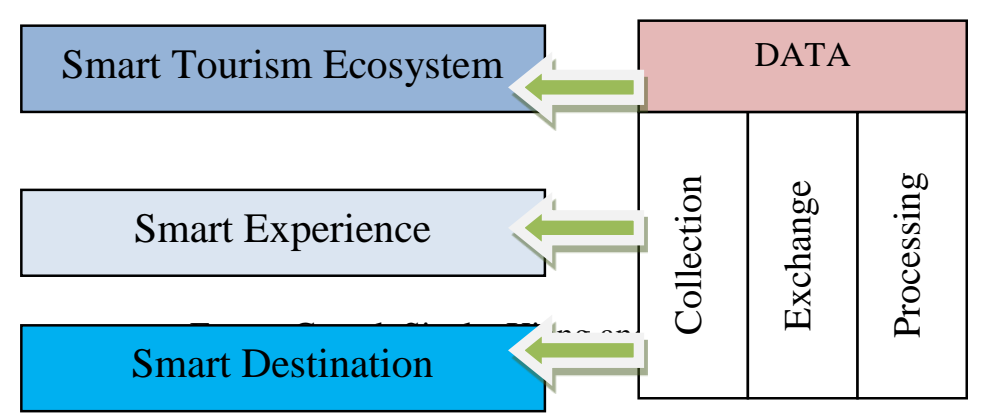

"Smart tourism ecosystem" is characterized according to its complexity and dynamically that initiates and supports the exchange of resources and co-creation (Buhalis \& Amranggana, 2014), and interconnection of stakeholders including public and private collaboration that is results in more open and technology-focused of infrastructure and data (Gretzel, Sigala, et al., 2015).

It is necessary to note that the three layers of data collection; exchange of information that support connectivity; and processing layer that is about analysis, visualize, integration and intelligent of data using extent across the three components (Tu \& Liu, 2014).

With the user-oriented of these systems that aim to accommodate tourists by anticipating their needs and recommendations about tourism activities and services. The systems also aim to enhance user experience by providing location-based customized information and interactive services. Additionally, empowering tourists to share their experience that help others in making 
decision (Gretzel, Werthner, Koo, \& Lamsfus, 2015). Therefore, development of these system should be collaboration, open and empowering full autonomy to stakeholders in order to enhance tourists experience and relevant tourism business (Yoo, Sigala, \& Gretzel, 2015).

\section{Methodology}

Promoting Phetchaburi Tourism Using the Royal Projects Trail Tourism Application as a Main Tool project divided the study into 2 phases.

Phase 1: Using research and development process to develop the Royal Trail Tourism Application by

1) Collecting primary data from interviewing of the government officers working in Petchaburi about the information required in the application and benefits of the application to stakeholders.

2) Collecting secondary data from relevant documents about developing application.

3) Developing application using hybrid application tool with supporting framework in order that the application can be run on both android and iOS.

Phase 2: Using PAR (Participatory Action Research) to enhance tourism development stakeholders' participation, because this phase aimed to provide opportunities to local communities to raise their voice, develop local tourism trial, and contribute tourism development knowledge to stakeholders by holding Mobile Marketing Workshops to promote Phetchaburi tourism. Providing local communities opportunities to inform tourists their products and service through application.

Figure 2 Research Framework

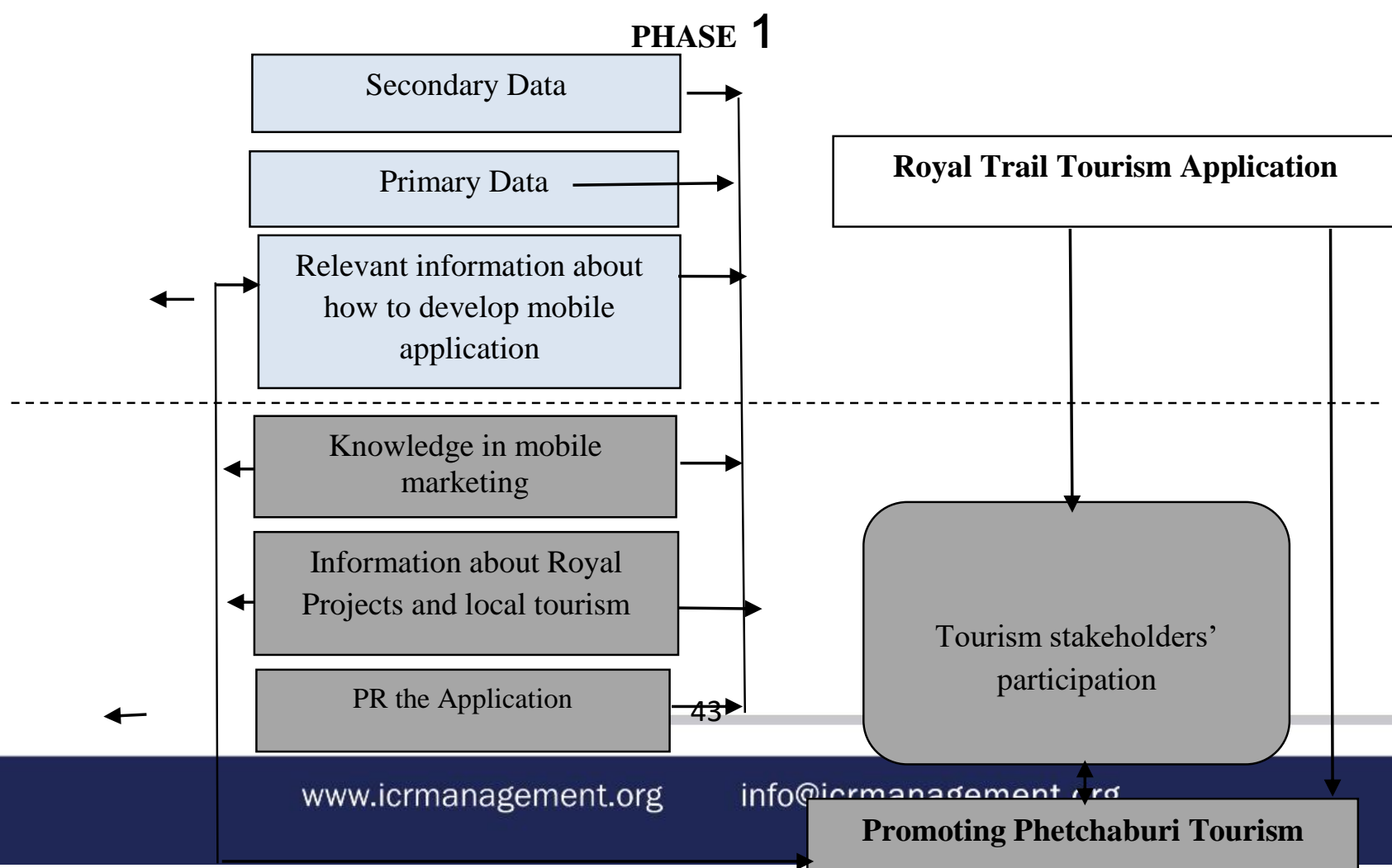




\section{Conclusion of results and findings}

\section{Phase 1: Using research and development process to develop the Royal Trail Tourism Application}

From interviewing of 6 government officers, the majority of the key informants recommended that the information required in the mobile app including the Royal Projects' maps, information about the projects, operating hours, approximate time spending in the project's area, projects' contributions to communities, products and services of each projects (if there is any), nearby tourists destinations, recommended food and beverage services, local communities' products (OTOP), public transport termination, petrol services, emergency numbers, especially; special discount of accommodation or products and services for tourists who download the application.

The Royal Projects' Trail app was developed based on primary and secondary data. It was designed to be easy to use and fit the mobile screen with simply functions. In addition, users can communicate with others users through the application. For users' convenience, the royalprojects@phetchaburi can be downloaded from App Store for iOS mobile and from Google Play for android mobile (Figure 3). Using Zero Rating concept, the strength of the app is that users can easily download the application without expense. The weakness of the app is it high competitiveness from others frees download mobile apps. Therefore, promoting stakeholders in using the application is necessary.

Figure 3 royalprojects@phetchaburi in App Store and Google Play

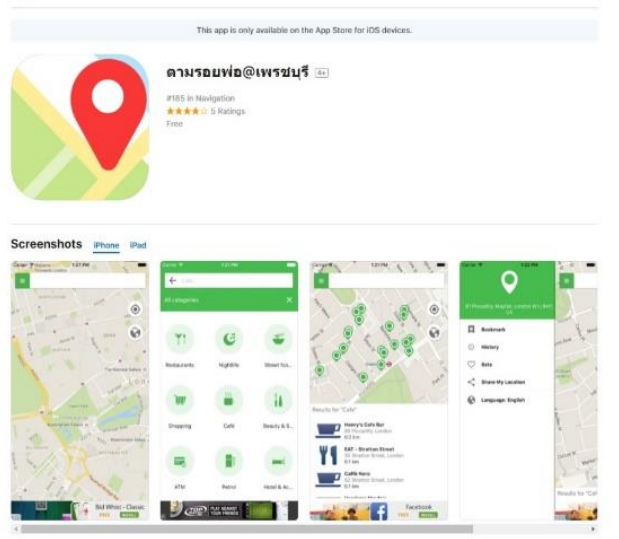




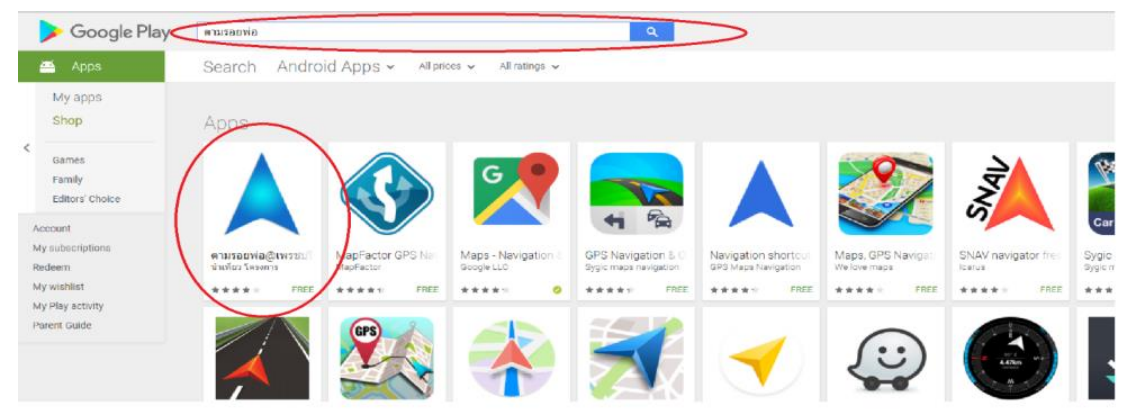

\section{Phase 2: Using PAR (Participatory Action Research) to enhance tourism development stakeholders' participation}

The location selected for this study including:

1) Cha-am District (Coordinated with Hub Kapong Demo Cooperative Center) because there are 8 of the Royal Projects located in Cha-am. There were 26 members of Hub Kapong Demo Cooperative Center attending the Mobile Marketing workshop.

2) Tayang District (Coordinated with Tayang Settlement Cooperative) because there are 5 of the Royal Projects located in Tayang. There were 29 members of Tayang Settlement Cooperative attending the Mobile Marketing workshop.

3) Talard District (Coordinated with Talard Agricultural Cooperative) because there is one of the Royal Projects located in Talard and Talard Agricultural Cooperative is one of the biggest cooperative in Petchaburi with more than 10,000 members. There were 58 members of Talard Agricultural Cooperative attending the Mobile Marketing workshop.

There were a total of 113 cooperatives' members from Cha-am, Tayang and Talard attending the workshops. The content of the workshops included mobile marketing concept, what is mobile app and what benefit it will contribute to tourists and communities, and how the app worked.

From the study, it can be concluded that to initiate a collaboration networking we should begin with cooperatives organizations in that areas for public relation and coordination to their members because the majority of farmers in Phetchaburi are members of the local cooperatives. Members of the cooperatives are voluntarily involved in activities recommended by the cooperative. Cooperative organizations have responsibility in supporting members' careers in terms of saving and lending money, development of local product and contribution of knowledge required. 
In addition, every cooperatives in Phetchaburi working in coordination with others, therefore; starting the public relation of the application to 3 cooperatives may be a good start for the sustainability of the application by extending users to other cooperatives and sponsored the app. In order to apply Zero Rating to the royalprojects@ phetchaburi app, the cooperative organizations should be convinced that the app benefits their members in terms of marketing and enhancing participation in tourism development. To promote tourists in downloading the app, free download is not promising, users should be rewarded from download and use the app such as getting discount on products/services. In addition, with limited budget, the app is just a demo one that need more fund and support to be completed. Whenever the app is sustain, it was hope that Phetchaburi will move toward smart city and smart tourism destination.

\section{Acknowledgement}

This project was funded and supported by the Thailand Research Fund (TRF) and Silpakorn University

\section{References}

Azori, L, Iera, A, \& Morabito, G. (2010). The Internet of Things: A Survey. Computer Network, 54(15), 1787-2805.

Buhalis, D, \& Amranggana, A. (2014). Smart Tourism Destinations. In Z Xiang \& I Tussyadiah (Eds.), Information and Communication Technologies in Tourism 2014 (pp. 553-564). Heidelberg: Springer.

Eptein, M., \& Vergani, S. (2006). History unwired: mobile narrative in historic cities. In paper presented at the working conference on advanced visual interfaces.

Gretzel, U, Koo, C, Sigala, M, \& Xiang, Z. (2015). Special Issue on Smart Tourism: Convergence of Information Technologies, Experiences, and Theories. Electron Markets, 25(2015), 175-177.

Gretzel, U, Sigala, M, Xiang, Z, \& Koo, C. (2015). Smart Tourism Foundation and Developments. Electron Markets, 25(2015), 179-188.

Gretzel, U, Werthner, H, Koo, C, \& Lamsfus, C. (2015). Conceptual Foundations for Understanding Smart Tourism Ecosystem. Computers in HUman Behavior, 50(2015), 558-563.

Harlaka, R. (2017). Mobile UX: Shifting Requirements for Marketers. In Mobile Marketing Association (MMA) (Ed.), APAC 2016 Yearbook: MMA.

Hunter, W. C, Chung, N, Gretzel, U, \& Koo, C. (2015). Constructivist Research in Smart Tourism. Asia Pacific Journal of Information Systems, 25(1), 105-120.

Koo, C, Gretzel, U, Hunter, W. C, \& Chung, N. (2015). The Role of IT in Tourism. Asia Pacific Journal of Information Systems, 25(1), 99-104.

Lazer, D, Pentland, A. S, Adamic, L, Aral, S, Barabasi, A. L, Brewer, D, \& Van Alstyne, M. (2009). Life in the Network: the Comming Age of Computational Social Science. New York: Science.

Li, Y, Hu, C, Huang, C, \& Duan, L. (2017). The Concept of Smart Tourism in the Context of Tourism Information Services. Tourism Management, 58(2017), 293-300.

Ma, Y, \& Liu, J. (2011, 24/08). The Enormous Prospects of the Smart Tourism Applications. China Tourism News. 
Mense, R. (2017). Joining Data and Creativity to Set Your App Apart. In Mobile Marketing Association (MMA) (Ed.), APAC 2016 Yearbook: MMA.

Mobile Marketing Association (MMA). (2014). Mobile: The Relationship Channel (version 4.4). Online: MMA.

Mobile Marketing Association (MMA). (2017). Sponsored Data e-Mobile Marketing (5 ed.): MMA.

Mobile Marketing Association (MMA). (2019). Mobile Marketing Association Reveals Brands Need a "First Second Strategy". Retrieved from https://www.mmaglobal.com/news/:

Nayyar, A. (2017). From Local to Global: Mobile Exellence in Asia. In Mobile Marketing Association (MMA) (Ed.), APAC 2016 Yearbook: MMA.

Park, J. H, Lee, C, Yoo, C, \& Nam, Y. (2016). An Analysis of the Utilization of Facebook by Local Korean Governments for Tourism Development and the Network of Smart Tourism Ecosystem. International Journal of Information Management, 36(2016), 1320-1327.

Sigala, M, Christou, E, \& Gretzel, U. (2012). Web 2.0 in Travel Tourism and Hospitality: Theory, Practice and Cases. New York: Ashgate Publisher.

Tu, Q, \& Liu, A. (2014). Frame Work of Smart Tourism Research and Related Progress in China. Paper presented at the International Conference on Management and Engineering (CME 2014).

Wang, D, \& Xiang, Z. (2012). The New Landscape of Travel: A Comprehensive Analysis of Smartphone Apps. In D Wang \& Z Xiang (Eds.), Information and Communication Technologies in Tourism 2012 (pp. 308-319). Vienna: Springer.

Xiang, Z, Wang, D, O' Leary, J. T, \& Fesenmaire, D. R. (2014). Adapting to the Internet: Trends in Travelers' Use of Web for Trip Planning. Journal of Travel Research, in press. Doi: $101177 / 0047287514522883$.

Yoo, K. H, Sigala, M, \& Gretzel, U. (2015). Exploring TripAdvisor. In R Egger, I Gula, \& D Walcher (Eds.), Open Tourism-Open Innovation, Crowdsourcing and Collaborative Consumption Challenging the Tourism Industry. Heidelburg: Springer Verlag. 